\title{
University Mathematics Lecturing as Modelling Mathematical Discourse
}

\section{Olov Viirman ${ }^{1}$ (1)}

Accepted: 7 February 2021 / Published online: 24 March 2021

(C) The Author(s) 2021

\begin{abstract}
The lecture format, while being the subject of much criticism, is still one of the most common formats of university mathematics teaching. This paper investigates lecturing as a means of modelling mathematical discourse, sometimes highlighted in the literature as one of its most important functions. The data analysed in the paper are taken from first-semester lectures given by seven mathematics lecturers at three Swedish universities, all concerning various aspects of the function concept. Analysis was carried out from a commognitive perspective, which distinguishes between objectlevel and meta-level discourse. Here I focus on two aspects of meta-level discourse: introducing new mathematical objects; and what counts as valid endorsement of a narrative. The analysis reveals a number of metarules concerning the modelling of mathematical reasoning and behaviour, both more general rules such as precision and consensus, and rules more specifically concerning construction and endorsement of narratives. The paper contributes to a small but growing body of empirical research on university mathematics teaching, and also lends empirical support to previous claims about the modelling aspect of mathematics lecturing, thus contributing to a deepened understanding of the lecture format and its potential role in future university mathematics teaching.
\end{abstract}

Keywords University mathematics $\cdot$ Lecture $\cdot$ Discourse $\cdot$ Metarules $\cdot$ Commognition

Consider the following excerpt, taken from a lecture in a first semester pre-calculus course at a Swedish university:

I think that most of you already have a sense of what it is a function is, but perhaps you haven't seen exactly a definition. Because it is like this in

Olov Viirman

olov.viirman@edu.uu.se

1 Uppsala University, Uppsala, Sweden

Springer 
mathematics, that all the words we use we have to state exactly what we mean by them so that we completely agree, if I say that all functions have a certain property, then all have to agree with me on what, what objects is it that we are talking about. We have to agree about what we mean by the word function.

Here, the lecturer explicitly states a rule for doing mathematics: "In mathematics we have to state exactly what we mean". As most people who have done some mathematics probably agree, there are many such rules governing mathematical behaviour. However, these rules are not always explicitly formulated, as in the above excerpt, but rather implicit within the discourse. In this paper, I aim to display how the modelling of such rules is a prominent aspect of the discourse of mathematics lecturing already in courses at the beginning university level, thus adding to findings by, for instance, Fukawa-Connelly (2012) on how lecturers in advanced proof-based courses model aspects of proving and providing further support to claims made by Pritchard (2010, 2015) and others about the modelling of mathematical behaviour as a function of university mathematics lecturing.

\section{Researchers' Perspectives on Lectures}

The lecture, that is, a teaching mode involving one teacher and a large group of students with communication mainly directed from the teacher to the students, continues to be one of the most widely used modes of teaching at universities around the world. However, the use of the lecture format has been the subject of heated debate among scholars of university education for many years. Although some mathematics education researchers (e.g. Alsina, 2001; Mason, 2002) have expressed scepticism about the value of the traditional lecture, the harshest criticism of the lecture as an effective mode of teaching has been voiced by general education scholars (e.g. Biggs \& Tang, 2011; Bligh, 2000). Bligh, drawing on various empirical studies, identifies four distinct kinds of objectives a lecture might have: The acquisition of information; the promotion of thought; changes in attitudes; and behavioural skills (Bligh, 2000, p. 4). He concludes that lectures are as effective as other methods for transmitting information, but less effective regarding the other objectives. On the other hand, some scholars, both of mathematics education (e.g. Pritchard, 2010; Rodd, 2003) and of general university education (e.g. Friesen, 2011; Jones, 2007) have argued the continued relevance of the lecture format. It has also been claimed, for instance by Neumann (2001), that much of the criticism of the lecture format fails to consider differences between academic disciplines. As remarked by Pritchard (2010), this tends to make this criticism less relevant to university mathematics education.

However, the above debate is rarely informed by empirical research based on observations of actual lecturing. Furthermore, much of the existing research on university mathematics teaching practice tends to reduce teaching to its form, and this is particularly true of research on lectures: "(T)he technique commonly called 'lecture' is particularly subject to this reductionist approach, as what is generally meant by the term - a discourse given before an audience - actually masks a myriad of specific 
pedagogical behaviours such as distinct rhetorical strategies and the use of different instructional technologies" (Hora \& Ferrare, 2013, p. 217-218). Indeed, one of the findings of my previous research on the lecturing practices of university mathematics lecturers (Viirman 2014a \& b, 2015) was that, despite great uniformity in the format of the teaching, there were major differences in teaching practices both regarding the treatment of the mathematical content and the various didactical routines employed. Hence, increased knowledge of these "myriad of specific pedagogical behaviours" is crucial to the debate on the value of lectures. One particular function of university mathematics lecturing, emphasised by Pritchard (2010) and others (e.g. Bergsten, 2007; Fukawa-Connelly, 2012; Oikkonen, 2009), but notably missing from Bligh's list, is the modelling of mathematical reasoning and behaviour. This is also highlighted by lecturers as one of the aims they are trying to achieve in their lectures (e.g. Artemeva \& Fox, 2011; Hemmi, 2010; Iannone \& Nardi, 2005; Weber, 2012). Still, little empirical research has focused on this aspect, and the few examples of such research that do exist (e.g. Fukawa-Connelly, 2012; Fukawa-Connelly \& Newton, 2014; Weber, 2004) concern teaching in so-called "proof-based" courses, that is, courses at a more advanced mathematical level. Pritchard (2015) claims that this modelling aspect is equally important in lectures at the beginning level. However, this claim is not based upon empirical investigation. Hence, taking a discursive perspective, the aim of the present paper is to investigate whether and how the modelling of mathematical reasoning and behaviour is manifested in lecturers' discursive practice at the beginning university level. Beyond contributing to a deeper understanding of the mathematics lecture format, the findings in this paper will also provide empirical support to arguments about the value of lectures in undergraduate mathematics teaching.

\section{Mathematics as Discourse}

A basic premise of the research presented in this paper is the view of mathematics and mathematics teaching as discursive activities. In this view, doing mathematics is seen as engaging in mathematical discourse and mathematical objects are seen as discursively constituted, that is, they obtain meaning and existence through the mathematical discourse. More specifically, the commognitive theory of Sfard (2008) is used to operationalize the notion of mathematical discourse. For Sfard, different types of communication are called discourses. We can thus speak of communities of discourse, made up of those individuals able to participate in certain discourses (Sfard, 2008, p. 91). It should be emphasized here that for Sfard thinking is viewed as a form of selfcommunication. Thus, whenever we are engaged in doing mathematics we are participating in mathematical discourse.

Sfard presents four characteristics that serve to distinguish specific discourses (Sfard, 2008, p. 133-135): Word use - words specific to the discourse or common words used in discourse-specific ways, for instance, 'function', 'linear transformation', 'proof'; visual mediators - visual objects operated upon as a part of the discursive activity, for instance, symbols and graphs; narratives - sequences of utterances describing objects, their relations and/or processes upon them, subject to endorsement or rejection within the discourse, for instance, definitions, theorems and formulas; and routines - repetitive patterns characteristic of the discourse. These repetitive patterns are the result of 
processes governed by rules, which can be of two types: object-level rules, which are "narratives about regularities in the behavior of objects of the discourse" (ibid, p. 201); and meta-level rules (henceforth 'metarules' for brevity), which "define patterns in the activity of the discursants trying to produce and substantiate object-level narratives" (ibid, p. 201). Hence, routines can be defined as sets of "metarules describing a repetitive discursive action" (ibid, p. 208).

Most of what we normally would describe as mathematical rules or facts belong to the object-level: differentiation rules, for example, or the fact that the sum of the angles of a triangle in Euclidean geometry equals $180^{\circ}$. The metarules govern the actions of the discursants, not the behaviour of the mathematical objects, and are thus of a different character. In contrast to the object-level rules, since they concern the behaviour of the people doing the mathematics they may evolve over time and vary between contexts. For instance, rules for what counts as valid substantiation of mathematical claims vary considerably between the primary mathematics classroom and the university lecture hall. Moreover, where the rules governing the mathematical objects are explicitly articulated as narratives in the mathematical discourse, metarules are often tacit. This is not always the case, however. Sfard distinguishes between endorsed metarules, which "are explicitly recognized as a person's own" (ibid. p. 204), and enacted metarules, which are inferred by an observer of the discourse. In the analyses that follow, we will see examples of both types. Furthermore, in contrast to object-level rules, metarules are often normative and value-laden. Again, though, not all metarules are norms. To qualify as a norm, a metarule must be endorsed by "those within the discourse community that count as experts" (ibid, p. 204).

A further important characteristic of meta-level rules is that they are constraining rather than deterministic. Of course, there are routines that are deterministic in nature; if two different discursants perform the same division algorithm correctly, the outcome will be the same. But more often than not, metarules serve rather to limit the possible discursive choices to a manageable number. Sfard (ibid, p. 206) compares to the rules of traffic: they do not tell us where to go, merely the proper behaviour while going there. Similarly, if asked to investigate the function $f(x)=\frac{1}{1-x}$, the average mathematics student will know more or less which discursive actions will be relevant, but neither the course of action nor the precise outcome is predetermined. Finally, metarules are contingent rather than necessary. This should be understood in contrast to object-level rules, which are necessary consequences of the definitions of the objects, ${ }^{1}$ whereas metarules "are the result of custom-sanctioned associations" (ibid, p. 206; compare Wittgenstein, 1978). Again, what actions the student is expected to perform when investigating the function $f(x)=\frac{1}{1-x}$ is something governed by convention, not logical necessity. It should be noted, however, that many such metarules do not appear at all contingent when viewed from inside the discourse. Take, for instance, the metarule that "when you want to disprove a statement, you only need one counterexample". To an insider of mathematical discourse this does not appear contingent, because it is so ingrained in the practice of mathematics. Still, a mathematics where one allowed for single exceptions to theorems is conceivable; it would not be the mathematics we know, and it would likely lead to all sorts of problems, but it would be $a$ mathematics.

${ }^{1}$ There are of course exceptions, for instance the parallel postulate, where a contingent choice leads to different geometries, but in the overwhelming majority of cases the claim holds true. 
Indeed, in many other discourses this idea is not at all strange; consider the expression "the exception proves the rule". 2

In conclusion, the above characteristics, although important, should not be taken as defining the notion of metarule. Rather, metarules are distinguished from object-level rules by what they regulate; the participation in the discourse, not the objects it concerns. However, the distinction between object-level and meta-level rules is sometimes relative to the discourse. For instance, a metarule of arithmetic such as "to multiply a sum of two numbers by a third number one can first multiply each addend and then add the products" turns into an object-level rule of algebra: $a(b+c)=a b+a c$ (see Sfard, 2008, p. 202 for more detail). An example of a metarule which is more clearly normative, context-dependent, tacit and contingent could be "when reasoning mathematically, visualisation is a valid tool".

In their normative character metarules are obviously related to sociomathematical norms (Yackel \& Cobb, 1996). However, from a discursive perspective, properties of the discourse itself are of greater relevance. In fact, a secondary aim of the paper is to contribute to the further development of commognitive theory by deepening the understanding of what characterises metarules, and of the roles they might play in mathematics teaching (in this case lecturing) discourse. Given the above, the question that the present paper seeks to address can now be formulated more precisely: what metarules relating to the modelling of mathematical activity can be discerned in the discursive practices of the lecturers?

\section{The Lecture in University Mathematics Education Research}

As late as ten years ago, Speer, Smith and Horvath 2010 expressed concern about the lack of empirical studies of university mathematics teaching. However, this situation is changing. For instance, some recent studies have analysed the narrative structure of lectures (Weinberg et al., 2016), described the discipline-specific uses of different pedagogical methods in lectures (Hora \& Ferrare, 2013), and investigated how lecturers' on-the-spot decision making affects the shaping of a lecture (Paterson et al., 2011).

A growing number of studies focus on characterising (aspects of) lecturing practice. An early example is Weber's (2004) case study of one university lecturer's teaching in an advanced mathematics course, with a focus on the teaching of proof. Weber identifies three distinct teaching styles: a logico-structural, a procedural and a semantic teaching style. Particularly the procedural style is concerned with modelling the techniques of proving, stated by the lecturer as a definite aim of this style of teaching (ibid, p. 128). Also focusing on the teaching of proof, Fukawa-Connelly (2012) presents a case study of lecturing in abstract algebra, highlighting the modelling aspect of the lecture: "The principal means of instruction in this case might be exposing students to the cognitive processes of doing mathematics. Although the mathematical tasks done in class are not novel or challenging for instructors, they can still make

\footnotetext{
${ }^{2}$ In fact, this idea is not completely alien to established mathematical discourse: consider the mathematical notion of "almost everywhere", where a statement is deemed to hold true almost everywhere if it is true everywhere except on a set of measure zero.
} 
explicit the mental processes that instructors engage in when tackling these tasks" (ibid, p. 327). Fukawa-Connelly shows how the lecturer models certain aspects of the proof construction process, and how her use of questions also serves this purpose, modelling "the types of questions that a mathematician should ask while writing proofs" (ibid, p. 343). A related study (Fukawa-Connelly \& Newton, 2014) investigates a lecturer's use of examples in an abstract algebra class highlighting, for instance, the functions they serve in motivating definitions and claims.

A recent study involving both Fukawa-Connelly and Weber (Lew et al., 2016) investigates the effectiveness of lecturing in advanced mathematics. Using a video recording of a segment of a real analysis lecture for stimulated recall, Lew et al. compared the lecturer's account of what he aimed to convey to the students with students' accounts of the important aspects of the proof being presented, finding little overlap. Even when specifically shown those excerpts that the lecturer had highlighted as conveying specific points, the students rarely identified these points. A possible explanation suggested by Lew et al. is that most of the points the lecturer wanted to emphasize were only presented verbally in the lecture, and not in writing. Indeed, when examining the students' notes, these verbal comments only very rarely made it into the notes. On a related note, Weinberg et al. (2014) describe how students' different sensemaking frames shape what they are able to learn from lectures in abstract algebra, in particular those aspects of the lectures not primarily concerned with factual content.

Some fairly recent studies look at lecturing from a socio-cultural perspective. Thomas (2011) builds on activity theory to construct a model characterizing the teaching practice of a lecturer teaching linear algebra, identifying five nested goals of the teaching moving from 'engagement with mathematics' to 'mathematical competence'. Particularly relevant to the topic of the present paper is the action of verbalizing intentions, that is, the lecturer being explicit to the students about what his goals were, both regarding the mathematics and the learning of mathematics (ibid, p. 78-81). Petropoulou et al. (2014) use the 'Teaching Triad' (Jaworski, 2002) to study the teaching practice of a university mathematics lecturer teaching calculus. Their analysis suggests that the "lecturer's teaching is characterized by the way he supports students' engagement in the lecture and the way he familiarises them with mathematical production" (Petropoulou et al., 2014, p. 2221). Indeed, the lecturer emphasizes introducing students into advanced mathematical thinking as an aim of his teaching: "What I try to do is to teach students how to think mathematically...And I have to make them understand how someone thinks and produces mathematics" (ibid, p. 2225).

Many findings presented in this section on university lecturers' modelling of (aspects of) mathematical behaviour might be considered in terms of metarules. However, since they mainly concern the lecturers' conscious choices, for instance of questions or examples, they focus on the endorsed metarules. Apart from showing that the modelling of mathematical behaviour is present already in the beginning courses, the analyses in the present paper aim to exemplify and elaborate also on enacted metarules, that is, metarules that the students might infer from what the lecturers say and do.

\section{University Mathematics Lecturing from a Discursive Perspective}

The growing interest in discursive approaches to university mathematics education research (Nardi et al., 2014) has led to a number of studies looking at the discourse of 
mathematics lectures. Artemeva and Fox (2011) characterize mathematics lecturing from a linguistic perspective. Building on video recordings of 50 lecturers from several countries, they identify a teaching genre, common to all the lecturers in the study, which they label 'chalk talk'. This genre has several characteristics, the most important being the writing of mathematical symbolism, text, graphs and diagrams on the board concurrently with running commentary (verbalizing what they write) and metacommentary (talking about what they write) (Artemeva \& Fox, 2011, p. 355). The lecturers all "accounted for their use of chalk talk in their lectures as a means of providing their students with an experience of the processes of mathematics" (ibid, $\mathrm{p}$. 356, emph. in original). Artemeva and Fox describe the genre of 'chalk talk' in a highly nuanced manner. However, the linguistic focus imposes some limitations on their analyses. For instance, when discussing the roles rhetorical questions play in the lecturing practice they do not mention their use in guiding student mathematical reasoning, shown in my previous work (Viirman, 2015) to be a pedagogical routine used by the lecturers.

Also coming from outside the field of mathematics education research, Greiffenhagen's (2008) aim is studying the professional practices of mathematicians from a sociological perspective. Still, his paper contains a fine-grained analysis of a lecture in a graduate course in mathematical logic. His research is framed by ethnomethodology and conversation analysis, and thus very much focused on the mathematical discourse. Greiffenhagen points out as specific to the teaching of university mathematics "the fact that the lecturer spends most of the time writing at the board. In other words, the lecturer is predominantly not talking 'about' mathematics, but actually 'doing' mathematics at the board. (...) In other words, the lecture can be thought of as a recipient-designed demonstration of mathematical reasoning" (Greiffenhagen, 2008, par 35).

Within the mathematics education community, the research of Wood, Smith and colleagues (Wood et al., 2007; Wood \& Smith, 2004) is an early example of studying mathematics lectures from a discursive perspective, drawing on video recordings of a calculus lecture on de Moivre's theorem. Wood and Smith (2004) adopt a functional approach to language to investigate mathematical argumentation in a lecture setting. They describe lecturing as a mixed mode activity, and highlight some differences between the use of spoken and written language, where the spoken language is more informal and personalized than the writing on the board, which is in turn less formal and impersonal than the language in the textbook. Wood et al. (2007) focus on the use of multiple representations in the lecture, and how the lecturer uses verbal and nonverbal cues to organize the students' attention to the different modes of representation. "In this way, the students' experience switching representations modelled for them [by the lecturer]. (...) This modelling includes nuanced use of the English language as it is used within mathematics" (p. 912).

As suggested above, my own previous research (Viirman, 2014b, 2015) studies university mathematics lecturing from a commognitive perspective, focusing on the characteristics of the discourse of teaching the function concept and presenting classifications of mathematical and didactical routines, for instance concerning defining and the use of questions. Güçler (2013) uses the commognitive framework to identify some distinguishing features of one lecturer's discourse on limits. However, her main focus is on discrepancies between the lecturer's and the students' discourses 
on limits, and she emphasizes the need for making the metarules of the discourse explicit to students. In a follow-up study, Güçler (2016) investigates how such an instructional approach, focusing on the mathematical discourse of function, can help student learning, and concludes that although the students still had difficulties with the function concept they were able to identify to a greater extent the nature of these difficulties and what aspects of their discourse needed to be changed. Any such practice, however, requires an awareness on the part of the lecturer of the metarules to be conveyed, as well as of possible metarules already implicitly conveyed, and research such as that presented in this paper might be helpful in this regard.

\section{Method}

\section{Data Collection and Context of the Study}

The data analysed in this paper was collected for my doctoral thesis (Viirman, 2014a) and consists of video recordings of lectures from first-semester mathematics courses at three Swedish universities: one large internationally renowned, one medium-sized and more recently established, and one smaller with a mainly regional recruitment base. A total of seven lecturers participated in the study. They were selected from those willing to participate in the study and teaching first-year courses during the time available for data collection. At the two smaller universities this left me with too few participants to warrant further selection, but in the case of the larger university further choice was made aiming for diversity, in topics covered as well as in teaching experience and gender. Table 1 summarizes some relevant information about the seven lecturers (labelled in accordance with previous publications using the same data).

As can be seen from the table, the participants varied in gender and teaching experience (and also in age and educational background). However, they all shared an interest in developing their teaching, although none were involved in any form of educational research. For further detail on the background of the lecturers, see (Viirman $2014 \mathrm{a} \& \mathrm{~b}, 2015)$. As also shown in the table, the lectures were from different courses,

Table 1 Lecturers participating in the study

\begin{tabular}{llll}
\hline Lecturer & Gender & Years of teaching & Course and topic \\
\hline \multicolumn{2}{l}{ University } & A $($ large, old): & \\
A1 & F & $15-20$ & Preparatory calculus - introduction to functions \\
A2 & M & $<5$ & Basic algebra - introduction to functions (general, trigonometric) \\
A3 & M & $10-15$ & Linear algebra - introduction to linear transformations \\
A4 & M & $>30$ & Single-variable calculus - continuity \\
University & B (medium, recent) & \\
B1 & M & $20-25$ & Single-variable calculus - inverse trigonometric functions \\
B2 & F & $10-15$ & Basic algebra - introduction to functions \\
University & C (smaller, regional) & \\
C1 & M & $20-25$ & Linear algebra - introduction to linear transformations \\
\hline
\end{tabular}


but they all concerned various aspects of the function concept (including linear transformations). In the analyses in this paper one lecture - 90-120 min of teaching by each lecturer has been included. The courses were mainly aimed at engineering and computer science students, the exception being $\mathrm{C} 1$, who taught future land-surveyors. The number of students varied from about 40 to well over 100 .

\section{Analysis}

The video recordings were transcribed verbatim, speech as well as the writing on the board. I then analysed the transcribed lectures with the aim of identifying metarules concerning the modelling of mathematical behaviour suggested by the lecturers' discursive activities. In the first stage of the analysis, I examined the transcribed data along two different lines of inquiry. Firstly, I looked for explicit keywords or phrases indicating the normative aspects of discourse, either concerning the discourse of mathematics more generally - "In mathematics (...) we have to state exactly what we mean" - or the activity of specific discursants, like the lecturer or the students "geometric examples, "cause I think that is a good way of thinking about these things"; "when you think about a function, you should think about a rule". I also collected all examples of rhetorical questions, identified in previous analysis (Viirman, 2015) as questions asked for "storytelling" purposes, or to direct the students' attention, and hence potentially focusing students' attention on characteristics of mathematical reasoning or behaviour. Secondly, I looked for repetitive patterns (routines) in the lecturers' discourse, ways of doing mathematics occurring repeatedly throughout the lecture, and thus potentially suggesting to the students how mathematics could (or should) be done. Here, I made use of previous analyses aimed at identifying mathematical and pedagogical routines in the lecturing discourse (for more detail, see Viirman 2014a \& b, 2015).

In the second stage of the analysis, I more closely examined the discursive activity connected to the different examples found, in order to determine whether they could be construed as instances of metarules concerning the modelling of mathematical behaviour. In particular, I looked for statements concerned with the doing of mathematics rather than the properties and behaviour of the mathematical objects. For instance, who was attributed with agency? Did the lecturer talk about "I" or "we" doing things, or was behaviour attributed to the mathematical objects? The following two statements can serve as examples of the two types of discourse: "It is the function X-squared that I move one step to the right and two steps up"; "the function goes from A to B and the element $\mathrm{x}$ goes to the element $\mathrm{f}(\mathrm{x})$ ". I also searched for recurring patterns in the way the lecturers acted in particular situations. Were there specific discursive moves that they consistently made use of when engaging in particular routines, for instance? As an example, lecturer A3 repeatedly used geometric reasoning to endorse narratives, while lecturer $\mathrm{C} 1$ used everyday experience as a motivational device. At this stage in the analysis, a preliminary characterization of the potential metarules was constructed.

In the third stage I then compared and contrasted these different instances, using this comparative analysis to refine my categorization, in a manner akin to the constant comparative method of grounded theory (Charmaz, 2006). At this stage, I also decided to focus on two themes - the introduction of new mathematical objects and the endorsement of mathematical narratives. These themes, highlighted in (Viirman, 
$2014 b, 2015)$ as central to the discourse in the lectures under investigation, provided a rich enough variety of metarules to fulfil my aim, while at the same time corresponding to two classes of routines central to mathematical discourse (Sfard, 2008, p. 225). Finally, I selected a few episodes for more detailed analysis. This selection was made to be both informative, in that the episodes in a clear and concise way illustrated the metarules I wanted to describe, and representative, in that they exemplified metarules which I had observed elsewhere in the data. These episodes, and the results of the analysis, are presented in the following section, together with further examples taken from the whole set of data.

However, before moving on to the presentation of results, some explanatory notes regarding the unit of analysis and the question of lecturers' intentions might be useful. In the present study the unit of analysis is the discursive activity. Hence, I make no claims regarding the intention behind the lecturers' utterances, apart from what might be inferred from the discourse. When I claim that a certain utterance or sequence of utterances suggests a certain metarule, I base this claim solely on the function that the utterance(s) fulfil locally in the discourse, and I do not infer any intention on the part of the lecturer. For instance, when I claim that a question is rhetorical, this is not based on any supposed insight into the lecturer's thought processes, but is rather done in much the same manner that we, as participants in discourse, can infer that a question functions as rhetorical just by the way the discourse enfolds. Also, it should be pointed out that metarules are researcher's constructs (ibid, p. 203). I do not claim that the lecturers were aware of the metarules, or that their utterances were intended to convey these rules. Rather, the notion of metarule helps me as a researcher describe and explain the function that a sequence of utterances might serve in the discourse, thus providing a clearer picture of the discursive practice as a whole.

\section{Results}

Briefly describing the overall format of the lectures documented in this study, using characterizations given by Saroyan and Snell (1997) and Artemeva and Fox (2011), it can be said to be content driven 'chalk talk': the lecturer does most of the talking while writing on the board, the focus is on the mathematical content, and active student participation is limited. However, such a coarse-grained description is insufficient if we wish to gain a deeper understanding of what happens in a lecture. Indeed, looking closer at the discourse of mathematics and of mathematics teaching, significant differences in the teachers' discursive practices can be seen, despite their apparent similarity (Viirman, 2014b, 2015). Still, these different discursive practices have certain common functions in the lectures. In what follows I will use analyses of excerpts from four of the lectures, augmented with additional examples from the rest of the data, to illustrate ways in which the discursive practices of the lecturers serve the function of modelling mathematical reasoning and behaviour. It should be emphasized that the practices described below form part of the educational discourse of the lecturers, thus serving the function of modelling mathematical behaviour to newcomers to the discourse. That is, I do not claim that the metarules described below are necessarily endorsed, or even enacted, metarules of the discourse of professional mathematicians, much less that they were intended as such by the lecturers. 


\section{Introducing New Mathematical Objects}

The first two excerpts (from lecturers A1 and A2) illustrate two different ways of modelling the mathematical discourse connected with the construction of mathematical narratives - more specifically introducing new mathematical objects. In connection to the excerpts I will briefly outline the content of the lectures to provide some context. Lecturer A1 spent the first 10 min presenting three examples of functions, noting that these share the property of giving exactly one value of $y$ for each value of $x$, and then using the unit circle as an example of an object not having this property. She then defined the function concept, and spent the next 15 min checking if the examples fit the definition. After some discussion of the role of the domain and the range in the definition she spent the last 5 min before the break on an example of a "silly" function $\left(p: Z_{+} \rightarrow\{0,1\}\right.$ such that $p(n)=1$ if the decimal expansion of $\pi$ contains a row of $n 7$ 's, and $p(n)=0$ otherwise) to show that the notion of a rule need not imply a simple formula or even a way of calculating the values of the function. The $45 \mathrm{~min}$ after the break were spent on trigonometric functions - introducing radians; defining the general sine and cosine functions; using the unit circle to calculate their values for specific angles and derive relations between them; and sketching their graphs and introducing the tangent function.

The following excerpt ${ }^{3}$ is from the very beginning of the lecture:

To know what we are talking about, we have to start by saying exactly what we mean by a function

[The function concept]

I think that most of you already have a sense of what it is a function is

But perhaps you haven't seen exactly a definition. Because it is like this in mathematics, that all the words we use we have to state exactly what we mean by them so that we completely agree, if I say that all functions have a certain property, then all have to agree with me on what, what objects is it that we are talking about

We have to agree about what we mean by the word function

Let's just look at a few examples that we already have seen

(Presents three examples of functions: $f(x)=(x-1)$

${ }^{2}+2, g(x)=\sqrt{x}, h(x)=\sqrt{|x|}$, first as formulas, then as graphs)

Then let's look at what it is that- why are these functions?

When you think of a function you should think about, hmmm, you can think about a rule

You can think like this

Here, A1 explicitly formulated two related metarules for mathematical discursive practice: In mathematics we need to state exactly what we mean and in mathematics we all have to agree about what we mean. These endorsed metarules emphasize the need for clear and precise definitions, but also the social aspects of mathematical

\footnotetext{
${ }^{3}$ All excerpts have been translated from Swedish by the author. Text in [square brackets] indicates writing on the board. Text in italics describes teacher actions.
} 
activity and the role of consensus. However, her next move was not to provide a definition. Instead she said: "let's just look at a few examples that we already have seen". Of course, these examples were not selected at random, but rather to illustrate the specific concept that the lecturer aimed at introducing. Still, the way they were introduced in the lecture implicitly suggests another, enacted, metarule: generalizing from known mathematical objects is a way of introducing new mathematical objects. (Compare with the general discursive constructions Sfard (2008, p. 170) denotes as saming and encapsulating.) Lecturer A1 consistently acted according to this metarule throughout the lecture, when introducing new objects. For instance, later in the lecture she started off with the sine and cosine functions as defined using right triangles, familiar to students from secondary school, and used these as a starting point for a discussion of the general trigonometric functions. Returning to the excerpt above, after presenting a number of examples, both as formulas and as graphs, lecturer A1 turned to the question of what unites them. But instead of actually examining the examples, and possibly involving the students in the mathematical reasoning underlying the development of the definition, she simply told the students what to do: "when you think of a function you should think about, hmmm, you could think about a rule". Thus, the modelling of mathematical behaviour only goes so far - the discourse of lecturer A1 suggested a metarule for introducing new mathematical objects, but did not really exemplify how this could be done in practice. Observing how lecturer A1 presented the examples, she introduced them using algebraic realizations as formulas, but went on to draw their graphs, emphasizing both algebraic and geometric realizations. We will return to this aspect of the discourse in the next section, when discussing means of endorsement.

Searching for indications of this metarule in the discourse of the other lecturers, B1 covered a topic (inverse trigonometric functions) where new objects were rather constructed directly from known ones, while $\mathrm{C} 1$ did not emphasize definitions as strongly as the other lecturers. However, the metarule concerning the use of examples as motivation for definitions was prominent in the discourse of lecturers A4 and B2. Lecturer B2 even explicitly stated that this is the way she normally goes about introducing new objects (at least in a lecture setting):

Why do we need functions, how do we work with them?

And I will start as usual

I will begin with an example

Indeed, throughout her lecture, whenever introducing new objects, she began by presenting an example. In fact, as described in (Viirman, 2014a, 2014b) she often presented two examples differing precisely in the aspect to be defined. Lecturer A4, in his turn, when introducing the notion of continuity, began by recalling previous examples concerning how to calculate the limit of a polynomial $P(x)$ at a specific point, and how this amounts to calculating the value of the polynomial at that point, and then explaining how this particular property is the one that will be used to define continuity. In this way, he demonstrates how one can build on properties of familiar objects in order to construct new ones. 
On the other hand, when lecturers A2 and A3 introduced new mathematical objects they engaged in a contrasting discursive practice, exemplified in the following excerpt, from the beginning of lecturer A2's lecture. One might say that where lecturer A1 presented an inductive model of doing mathematics, A2 presented a deductive. After very briefly reiterating some of the main points from the previous lecture, he began by defining the function concept, and then spent 5 min introducing terminology and $10 \mathrm{~min}$ on different examples of functions. The next $15 \mathrm{~min}$ were devoted to descriptions of the function concept - the "function machine" and the graph. The last $15 \mathrm{~min}$ before the break were spent on injective functions - definition, examples and nonexamples. After the break he spent $15 \mathrm{~min}$ on invertibility - finding inverses, the relation between domain and range of the function and its inverse. The next $15 \mathrm{~min}$ were spent on surjectivity and bijectivity, including constructing a bijection between the natural numbers and the integers. He then spent $10 \mathrm{~min}$ on function composition and the last 5 min on solving a problem - showing that a given function is injective and finding its inverse.

Again, the excerpt is taken from the very first part of the lecture:

What we haven't learnt is how to connect two sets in the sense that to every element in the first set we associate an element in the second set, and this is what functions do

To be able to describe what functions are we begin by defining them

(Presents, in some detail, a formal definition of the function concept, summarized as: Given two non-

empty sets $A$ and $B$, a function from $A$ to $B$ is a rule that to every $x$ in $A$ assigns an element ${ }^{4}$ in $B$ )

Well, these- this is of course a very, well in its- in some sense a very concrete but still a very abstract definition, you have run into functions before in upper secondary and in other maths courses if you have taken any, and there they never cover this, instead they assume that everyone knows more or less what a function is

But now that we know this we can do some examples of it

(Presents examples of different types of functions, and introduces some terminology)

Now that we know what a function is, perhaps you want to visualize the function in a better way than just writing like this (points at the realization given on the board: $f: \mathbb{R} \rightarrow \mathbb{R}, x \mapsto x^{2}$ ), like this you don't see, OK, you know what the function does, but you don't get a very good conception of what it looks like, or what the function really is

So, how to visualize functions?

In the third line of this excerpt a metarule is explicitly stated: To be able to talk about a new mathematical object, we first need to define it. As in the case of lecturer A1, the importance of definitions is emphasized, but the discursive practice connected to them is different. Indeed, what immediately followed was a detailed presentation of a formal

\footnotetext{
${ }^{4}$ At this point, he did not mention that the element in B has to be unique, but he added this later. 
definition of function. Then the lecturer said: "Now that we know this we can do some examples of it". Hence, instead of serving as motivation for the definition, the examples served as illustrations of the definition already given. This suggests a model of mathematical practice closer to the deductive "definition-theorem-proof" (DTP) format described by Weber (2004, p. 116). A further example can serve to illustrate the approach of lecturer A2. Later during the lecture, talking about graphs of functions (objects familiar to the students from secondary school) as made up of pairs of points $(x, f(x))$, he stated: "but now it feels as if we have done something without defining it" and pausing to define the notion of 'ordered pair'. Indeed, throughout the lecture he consistently endorsed this metarule, explicitly stating that new objects need to be defined before we can talk about them. As seen in the excerpt above, he also contrasted this approach with how things were done "before in upper secondary and in other maths courses if you have taken any", suggesting that now is the time to start doing things more stringently. Lecturer A3 also followed this pattern, starting the lecture by giving a definition of 'linear transformation', and then spending the bulk of the lecture exemplifying and expanding on this notion. However, in his case the metarule was enacted rather than endorsed; the kinds of verbal cues used by lecturer A2 to call students' attention to the need for definitions were not present in the discourse of lecturer A3.

A difficulty with this metarule for newcomers to the discourse is knowing what new objects to introduce, and in the discourse of lecturer A2 there can be found a recurring pattern performing this function. In the very first line of the excerpt above, having recalled a certain piece of mathematics (in this case the basic operations on sets - union, intersection, complement etc.) he identified something that it cannot achieve (in this case connecting the elements of sets), thus providing motivation for the introduction of some new mathematical object. This suggests a metarule for mathematical discourse: the introduction of new mathematical objects can be motivated by gaps in the mathematical narratives already endorsed. This is in contrast to the case of lecturer A1, where known examples were used to find commonalities. The same pattern can be seen later in the excerpt: "Now that we know what a function is, perhaps we want to..." Again, starting from what you know, you identify a gap, and see what you need to fill that gap. Lecturer A2 uses this discursive device throughout the lecture, although sometimes the motivation comes after the definition, as in the following excerpt:

Now we get to the point of injectivity, why one wants a function to be injective (...)

This is the machine $f$. We can insert an $x$ and out comes a well-defined $f(x)$. (..) so, what if we can turn this machine around and put in $f(x)$ and get $x$ back? This does not always work (...) but the type of functions for which it works are injective functions.

However, this discursive pattern cannot be seen in the discourse of any of the other lecturers in the study. One might expect something similar to be found in the discourse of lecturer A3, since he takes the same deductive approach to defining, but as shown in (Viirman, 2015) he uses other types of motivational devices in his lecture. 


\section{What Counts as Valid Endorsement of a Mathematical Narrative?}

One of the distinguishing characteristics of a particular discourse is its endorsed narratives, and mathematical discourse is further characterized by the emphasis placed on endorsement practices, that is, on means of substantiation of mathematical narratives. Thus, endorsement practices are a potentially fruitful source of metarules concerning mathematical behaviour. Here, two excerpts (from lecturers A4 and C1) will illustrate two different approaches to endorsement, concerning both what counts as endorsed narratives and what are valid means of substantiation. Common to the excerpts is the use of rhetorical questions to model the discursive practice of mathematics. To contextualize the excerpts, I present brief outlines of the lectures. Lecturer A4 spent the first 15 min introducing and defining continuity and then exemplifying by examining the behaviour of the function $f(x)=\frac{1}{x-1}$ and sketching its graph. For the next 15 min he discussed how the rules of limits influence the rules of continuity and in particular that polynomials, rational functions and compositions of continuous functions are continuous. The last $15 \mathrm{~min}$ before the break were spent discussing the behaviour of discontinuous functions, giving a classification of possible discontinuities. After the break he spent $10 \mathrm{~min}$ on an example of a removable discontinuity, and then 5 min on strange functions, using the Dirichlet function as an example. The next 15 min were devoted to theorems about continuous functions, such as the intermediate value theorem, with some substantiating arguments but without formal proofs. Finally, he spent $10 \mathrm{~min}$ on solving a problem about estimating the locations of the zeros of a polynomial.

The following excerpt is from the part of the lecture devoted to the function $f(x)=\frac{1}{x-1}$. Having made the claim that this function is continuous everywhere in its domain, he continued:

And then we know - if someone were to twist your arm and say: How do you know that? Then it's precisely because of the good old rules of limits

When a quotient of two polynomials, and we can use previous results about standard limits and rules just like before

And so $\mathrm{f}$ of $\mathrm{x}$ equals one divided by $\mathrm{x}$ minus one is a continuous function

[So $f(x)=\frac{1}{x-1}$ is a continuous function]

We remove the points where it gets messy

What does this function look like?

(Draws a coordinate system, highlights $x=1$ as the crucial point)

So, what happens to this function when $\mathrm{x}$ is greater than one?

Well first of all we see that when $\mathrm{x}$ is larger than one then that [points at the denominator] is positive, the whole of the number is positive, so it lies above the $\mathrm{x}$-axis

What happens when $\mathrm{x}$ becomes really big?

It becomes really small and positive

Central to the discourse in this excerpt is the way mathematical reasoning is structured, with new claims building on previous results. We see this in the first line of the excerpt, 
in the rhetorical question "How do you know that?" If a claim is made, then we must be able to present support for it, and this support is provided by referring back to previously known mathematics. This pattern occurred repeatedly in the discourse of lecturer A4, as in the following excerpts, taken from different parts of the lecture:

It isn't obvious that it is like this, it isn't a property that all functions have, but for us this was a consequence of what?

Two things. The calculation rules for limits (...) and the standard limits.

You need to build a store of continuous functions, so that in arguments later you can say: well this is continuous, hence

this and this and this holds.

You know from high school that you have solved this kind of problems using derivatives, find the maximum volume of a

tin can, and so on. The existence of such extreme values follows from continuity.

The metarule governing this pattern can be formulated as follows: mathematical narratives should be substantiated using already endorsed mathematical narratives. This might appear trivial from the standpoint of an experienced insider to mathematical discourse, but it should be kept in mind that the target audience here is first-semester students, for whom the need for and the means of substantiation might not be clear. It should perhaps be pointed out as well that the means of substantiation need not, and in most cases did not, consist of formal proof. Indeed, although an emphasis on substantiation routines can be found in the discourse of most other lecturers in the study (the exception being lecturer $\mathrm{C} 1$, as will be shown below), the types of narratives that can serve as valid means of endorsement differed. This concerned the role of proof, but also the role given to different visual mediators. For instance, as mentioned in the last section, lecturer A1 presented both algebraic and graphical realizations of her examples of functions, and when first describing the defining characteristic of functions, she did this using a graphical argument akin to the vertical line test. However, when showing that the given examples fulfilled the criteria of the definition she consistently used algebraic means of substantiation rather than graphical. This could be interpreted as a conflict between her endorsed and enacted metarules concerning substantiation of mathematical narratives, at least in this context. The enacted metarule might be formulated as: algebraic realizations are the preferred means of endorsement of mathematical narratives. However, this enacted metarule seems to be dependent of what types of mathematical narratives are to be endorsed. Later in her lecture, when discussing trigonometric functions, lecturer A1 repeatedly used geometrical narratives to substantiate claims. Lecturers A3 and B2 more consistently utilized both algebraic and graphical means of substantiation. For instance, lecturer A3 used drawings of vectors to show that rotation in the plane is a linear transformation, and lecturer B2 provided graphical methods of determining injectivity and surjectivity. In fact, when asked by a student whether this method would be acceptable in an exam, she responded:

Yes, of course! Because this is correct, it is a completely mathematical method, there is nothing wrong with it. 
Thus, to these lecturers, graphical and algebraic realizations are equally valid means of endorsement of mathematical narratives.

I wish to make one final point regarding the excerpt from lecturer A4, which is clearly related to the notion of modelling mathematical practice, although not so easily formulated in terms of a metarule. It provides a good example of a particular way of using rhetorical questions, used by all the lecturers in the study to a varying extent (examples of such rhetorical questions can be found in all the previously presented excerpts, for instance). Given an example of a mathematical object (in this case the function $\left.f(x)=\frac{1}{x-1}\right)$, lecturer A4 proceeded by asking himself questions: "What does this function look like?" "What happens to this function when $\mathrm{x}$ is greater than one?" "What happens when $\mathrm{x}$ becomes really big?" In this way he voiced the questions he would ask himself if faced with a similar task when working on some mathematical problem, thus modelling mathematical enquiry by example.

Moving to the last of the four excerpts, lecturer $\mathrm{C} 1$ first spent $15 \mathrm{~min}$ discussing linear independence, before moving on to the main topic: linear transformations. This was approached in a roundabout way, referring back to the way the function concept was introduced in school and spending $10 \mathrm{~min}$ on different descriptions of functions from $\mathrm{R}$ to $\mathrm{R}$ and on examples from everyday life. Discussion of the higher-dimensional case was followed by $25 \mathrm{~min}$ on matrices as the higher dimensional equivalent of linear functions, with examples, including examples from outside mathematics, like drawing technical blueprints as an example of projection. The second half of the lecture began with the definition of linear transformation, followed by $10 \mathrm{~min}$ of examples. The last 15 min were spent on one-to-one mappings, with examples, and the connections between one-to-one, invertibility and linear independence.

The following excerpt is taken from the middle of the first half of the lecture:

What does it look like when we do a linear transformation in two dimensions?

What does it look like when we were in our world that we were in just now (before he started talking about linear transformations he had done some work on vectors in 2-space) when we had a two-dimensional world?

When we had this one zero and zero one that were at right angles?

Those are my $x$-values, then this [points at the graph of $y=2 x+1$ ] should be twodimensional

And what about the transformation?

Well we don't really know, it could be two-dimensional or one-dimensional

What happens if we think, we started with this sometime last week, and I said think, you've all been doing this I said

You've all been playing with Photoshop or something

What happens if I want to decrease the width of my image?

Suddenly we don't want to look quite as fat as we are

And then you do like this, to get that feeling you multiply all widths by zero point eight

And then you become taller, or you become as tall but thinner, right?

(...)

What is it that we do? 
We make a transformation, we multiply all widths by zero point eight and keep the height

What does this look like?

We have a two-dimensional image that we see on the screen that we start with, and after a while we get another two-dimensional world, where we have changed something so that something has happened

What's going on here?

Evident from this excerpt is the large number of questions. Indeed, the extensive use of rhetorical questions is perhaps the most significant characteristic of the discursive practice of lecturer C1 (Viirman, 2015, p. 1176). However, the purpose they serve, and the means employed for answering them, differs markedly from lecturer A4. Where he employed previously endorsed mathematical narratives to answer his questions, lecturer $\mathrm{C} 1$ turned to a concrete example from the world outside of mathematics in this case using Photoshop. This way of appealing to the students' every day experience was something lecturer $\mathrm{C} 1$ did repeatedly throughout the lecture. For instance, where lecturer A3 introduced orthogonal projection onto a generic vector as an example of a linear transformation, lecturer $\mathrm{C} 1$ started by talking about making technical blueprints and how taking the view from the front, from the side or from above corresponds to mapping one of the coordinates to zero, without mentioning the term 'projection'. The same mathematical idea is in the first case described as a purely mathematical, albeit geometric, problem, and in the second case as a way of interpreting a practical problem in mathematical terms. Similarly, when discussing different bases, and the role of the origin, lecturer $\mathrm{C} 1$ did this in the context of the practical task of conducting measurements for constructing a map (highly relevant for future land-surveyors). A further noteworthy feature of the excerpt above, and indeed of the lecturing practice of $\mathrm{C} 1$ more generally, is the small amount of mathematical notation and symbolic manipulation used. In fact, substantiation of mathematical narratives played a very limited role in the discourse of lecturer $\mathrm{C} 1$, at least in the observed lecture. Narratives were not endorsed through intra-mathematical substantiation, such as algebraic manipulation or geometric arguments. Instead, endorsed mathematical narratives were constructed building on real-world experience. This suggests another metarule: the world outside mathematics is a valid source of endorsed mathematical narratives. This way of engaging in mathematical activity stands in stark contrast to that suggested by the discursive practices of the other lecturers in the study, where the world outside of mathematics is almost completely invisible.

\section{Conclusions and Implications for Mathematics Lecturing}

In the previous sections I presented a number of metarules of mathematical discourse. These were either endorsed, that is, explicitly present in the discourse of the lecturers of the study, or enacted, that is, suggested by their discursive practice. These metarules concerned different aspects of mathematical activity. First, there were metarules that concerned general aspects of mathematical behaviour:

- Precision ("In mathematics we need to state exactly what we mean.") 
- Consensus ("In mathematics we all have to agree about what we mean.")

Second, there were metarules concerning the introduction of new mathematical objects:

- Definitions first ("To be able to talk about a new mathematical object, we first need to define it.")

- Examples first ("Generalizing from known mathematical objects is a way of introducing new mathematical objects.")

- Gaps point forward ("The introduction of new mathematical objects can be motivated by gaps in the mathematical narratives already endorsed.")

Third, there were metarules concerning the endorsement of mathematical narratives:

- Intra-mathematical endorsement ("Mathematical narratives should be substantiated using already endorsed mathematical narratives.”)

"Algebraic realizations are the preferred means of endorsement of mathematical narratives."

"Graphical and algebraic realizations are equally valid means of endorsement of mathematical narratives."

- Extra-mathematical endorsement ("The world outside of mathematics is a valid source of endorsed mathematical narratives.")

These rules all concern "the activity of the discursants trying to produce and substantiate object-level narratives" (Sfard, 2008, p. 201), that is, they are indeed metarules. Moreover, they are largely tacit, although some of them are explicitly endorsed by the lecturers. They are normative, since they are endorsed or enacted by the lecturers as representatives of the leading discourse, and they are context-dependent. They are constraining rather than deterministic, and contingent in the sense of being governed by convention rather than logical necessity. Indeed, some of them are even mutually contradictory. Hence, I make no claims that these particular metarules are characteristic of mathematical discourse generally. Indeed, viewed as such some of them can seem quite trivial, and some might meet with some opposition. Rather, the point I'm making is that they are characteristic of the particular instances of university mathematics lecturing discourse analysed. In a way, the main finding of this study is not so much the specific metarules themselves, but rather that analysis of lecturing practice has revealed the presence of metarules serving to model mathematical reasoning and behaviour, at least in the seven cases studied here. Hence, the results of this study lend further empirical support to the claim made by Pritchard (2010) and others, and highlighted by lecturers in interviews (e.g. Iannone \& Nardi, 2005; Petropoulou et al., 2014), that modelling mathematical reasoning and behaviour is a function of the university mathematics lecture. Some such evidence has already been provided by, for instance, Fukawa-Connelly (2012); Fukawa-Connelly \& Newton, 2014), but then in the context of more advanced mathematics courses, and focusing on the practice of proving. Proof and proving was not a central feature of the lectures analysed in this paper, but the findings indicate that such modelling can concern also more general 
mathematical activity, and be a feature of lectures already at the beginning university level. Indeed, the fact that the lectures are aimed at newcomers to university-level mathematical discourse might serve to explain the presence of such seemingly trivial metarules as the need for intra-mathematical substantiation. On the other hand, the presence of the "gaps point forward" metarule only in the discourse of lecturer A2 might also be explained by this fact. This metarule is much less straightforward than those used by the other lecturers for motivating the introduction of new mathematical objects, and it is probably quite difficult for a beginner to the discourse to grasp. Indeed, as mentioned in (Viirman, 2014a, 2014b), lecturer A2 had much less teaching experience than the other lecturers in the study, and this might be a case of the mathematician taking precedence over the teacher (Paterson et al., 2011).

Considering the target audiences of the lectures, the variety in the metarules identified, and hence in the models of doing mathematics that they suggest, becomes of interest. The metarule for endorsement of mathematical narratives identified in the discourse of lecturer $\mathrm{C} 1$ highlights every day experience as a valid source of endorsed mathematical narratives, in contrast to the discourse of the other lecturers in the study, where intra-mathematical substantiation is the norm. Lecturer A4, for instance, emphasizes the substantiation of claims as central to mathematical activity, thus contributing to a view of mathematics as a cumulative process, where statements build on previous statements and where validity is judged within the mathematical discourse itself. This kind of discourse environment might help enculturate the students into the discourse of university mathematics. Possibly, lecturer C1, through his emphasis on the extra-mathematical, is adapting to the fact that he is lecturing to future land-surveyors, for whom mathematics is largely a tool rather than an end in itself. In the light of this, and given that most of the lectures in the study were aimed at first-year engineering students, it is perhaps somewhat surprising that the world outside mathematics does not play a larger role in the discourse, even for the lecturers mainly emphasizing intra-mathematical substantiation. In fact, even lecturer $\mathrm{C} 1$ mostly uses everyday examples rather than examples originating in the students' main field of study. An exception is the example mentioned above, where the activity of doing measurements for maps is used to discuss the need for preferred coordinates.

Further differences between the discursive practices of the lecturers can be seen in what types of mathematical narratives count as valid means of substantiation. All lecturers in the study make extensive use of multiple forms of representation, as described by Wood et al. (2007), but the functions given to these different representations vary. The enacted substantiation routines of lecturer A1 favours algebraic narratives, with graphical realizations used solely for illustrative purposes, at least in the context of algebraic functions. When trigonometric functions are concerned, she instead favours graphical realizations. It is very likely that this difference can be traced to the geometric origins of the trigonometric functions, but whatever the cause her means of substantiation are apparently context-dependent. Lecturers A3 and B2, on the other hand, both move between graphical and algebraic realizations for substantiation purposes throughout their lectures, seemingly presenting a different picture of what counts as valid mathematical endorsement. It would be of interest to investigate whether these differences influence the way students engage in mathematical substantiation. 
Zooming out, and reflecting upon what more general conclusions regarding university mathematics lecturing practice can be drawn from the findings of this study, the way, for instance, lecturer A4 uses rhetorical questions to model the process of mathematical reasoning resonates with the findings of Fukawa-Connelly (2012), where the lecturer wants her students to encounter the "questions that a mathematician should ask while writing proofs" (ibid, p. 343). However, the findings suggest that this discursive device is not limited to just the teaching of proof, but can also be used to model mathematical reasoning more generally and at a less advanced level mathematically. The use of rhetorical questions in university mathematics lecturing is also discussed by Artemeva and Fox (2011), who describe how they are used in 'chalk talk' to signal transitions or to pause the action to make room for reflection, and also give some examples of rhetorical questions used as metacommentary (ibid, p. 362). The results of this study indicate that the modelling of mathematical reasoning practice, using questions to make the steps of the reasoning process more explicit, is another function of rhetorical questions within the 'chalk talk' genre. More generally, this study adds to the work of Artemeva and Fox by providing additional detail concerning the functions of lecturers' metacommentary, supplementing their linguistic perspective by highlighting ways in which metacommentary contributes to developing mathematical discourse.

From a commognitive standpoint, metarules are an important part of mathematical discourse, one which is perhaps sometimes overlooked in favour of the more explicit object-level rules, particularly in a university lecturing context. A secondary aim of this study was to contribute to theoretical development by elaborating on the role that metarules, and enacted metarules in particular, play in mathematics teaching discourse. The analyses presented in this paper indicate the presence of metarules, both endorsed and enacted, modelling mathematical reasoning and behaviour. However, the interview data presented by Lew et al. (2016) suggest that more general ideas that the lecturer was trying to convey were lost in favour of facts and procedures. However, adaptation to the types of metarules of mathematical behaviour discussed in the present paper, such as the need for intra-mathematical substantiation of narratives, cannot be expected to be captured in interviews with students. As one of my own mathematics lecturers during my undergraduate studies once said: "this is the kind of thing you should have absorbed through osmosis". Investigating such adaptation, where the discursive practices of teachers are gradually incorporated into the discursive repertoire of the students, would have to involve analysis of changes in students' mathematical discourse over time.

A common feature of the lectures analysed in this paper and that of Lew et al. (2016) is that most metacommentary was only spoken, and not written on the board. Perhaps if what we want students to get from lectures is not only the facts and object-level rules of the discourse, but also the more general metarules, then we need to be more explicit about these metarules. In a recent study, Güçler (2016) has tried precisely such an instructional approach with some success. Also, Oikkonen (2009), having redesigned a calculus course to focus more explicitly on displaying the thinking behind the mathematics presented, could see positive results on pass rates. On the other hand, as Sfard (2008, p. 202) points out, metarules are often tacit, and for lecturers to make them explicit topics of study might not always be easy, or even desirable. Further research on these aspects of lecturing would be useful. However, studies such as this one, highlighting the functions that lecturing might serve beyond communicating 
mathematics at the object level, can help mathematics lecturers become more aware of how the discourse they engage in when lecturing may influence the way their students engage with the mathematics. Indeed, if students can be expected to infer enacted metarules from lectures, and adapt their mathematical behaviour accordingly, then becoming aware of the learning opportunities afforded not only by the mathematical facts and procedures presented, but also by how the mathematical activity is conducted, might also encourage lecturers to reflect upon the tacit assumptions behind the way they present and do mathematics in their lecturing practice.

Whatever the answer to such questions, I firmly believe that any discussion of the role of the lecture in future mathematics teaching at universities, whether among researchers or practicing lecturers, needs to be informed by research on actual lecturing practice. It is my hope that the present paper can contribute to a better understanding of the functions of mathematics lectures in this regard.

Acknowledgements Open access funding provided by Uppsala University. I wish to thank the university mathematics teachers who kindly agreed to participate in this study, and the anonymous reviewers who, with their insightful and enlightening comments, contributed greatly to the final shape of this paper.

Code Availability N/A

Data Availability N/A

\section{Declarations}

Conflict of Interest The author states that there is no conflict of interest.

Open Access This article is licensed under a Creative Commons Attribution 4.0 International License, which permits use, sharing, adaptation, distribution and reproduction in any medium or format, as long as you give appropriate credit to the original author(s) and the source, provide a link to the Creative Commons licence, and indicate if changes were made. The images or other third party material in this article are included in the article's Creative Commons licence, unless indicated otherwise in a credit line to the material. If material is not included in the article's Creative Commons licence and your intended use is not permitted by statutory regulation or exceeds the permitted use, you will need to obtain permission directly from the copyright holder. To view a copy of this licence, visit http://creativecommons.org/licenses/by/4.0/.

\section{References}

Alsina, C. (2001). Why the professor must be a stimulating teacher: Towards a new paradigm of teaching mathematics at university level. In D. A. Holton (Ed.), The teaching and learning of mathematics at university level: An ICMI study (pp. 3-12). Kluwer.

Artemeva, N., \& Fox, J. (2011). The writing's on the board: The global and the local in teaching undergraduate mathematics through chalk talk. Written Communication, 28(4), 345-379.

Bergsten, C. (2007). Investigating quality of undergraduate mathematics lectures. Mathematics Education Research Journal, 19(3), 48-72.

Biggs, J. B., \& Tang, C. S. (2011). Teaching for quality learning at university: What the student does. E-book (4th ed.). McGraw-Hill/Society for Research into Higher Education/Open University Press.

Bligh, D. A. (2000). What's the use of lectures? E-book (1st ed.). Jossey-Bass.

Charmaz, K. (2006). Constructing grounded theory: A practical guide through qualitative analysis. SAGE Publications. 
Friesen, N. (2011). The lecture as a transmedial pedagogical form: A historical analysis. Educational Researcher, 40(3), 95-102.

Fukawa-Connelly, T. P. (2012). A case study of one instructor's lecture-based teaching of proof in abstract algebra: Making sense of her pedagogical moves. Educational Studies in Mathematics, 81, 325-345.

Fukawa-Connelly, T. P., \& Newton, C. (2014). Analyzing the teaching of advanced mathematics courses via the enacted example space. Educational Studies in Mathematics, 87, 323-349.

Greiffenhagen, C. (2008). Video analysis of mathematical practice? Different attempts to "open up" mathematics for sociological investigation. Forum: Qualitative Social Research, 9(3), art. 32.

Güçler, B. (2013). Examining the discourse on the limit concept in a beginning-level calculus classroom. Educational Studies in Mathematics, 82, 439-453.

Güçler, B. (2016). Making implicit metalevel rules of the discourse on function explicit topics of reflection in the classroom to foster student learning. Educational Studies in Mathematics, 91, 375-393.

Hemmi, K. (2010). Three styles characterising mathematicians' pedagogical perspectives on proof. Educational Studies in Mathematics, 75, 271-291.

Hora, M. T., \& Ferrare, J. J. (2013). Instructional systems of practice: A multidimensional analysis of math and science undergraduate course planning and classroom teaching. Journal of the Learning Sciences, 22(2), 212-257.

Iannone, P., \& Nardi, E. (2005). On the pedagogical insight of mathematicians: 'Interaction' and 'transition from the concrete to the abstract'. The Journal of Mathematical Behavior, 24, 191-215.

Jaworski, B. (2002). Sensitivity and challenge in university mathematics tutorial teaching. Educational Studies in Mathematics, 51, 71-94.

Jones, S. E. (2007). Reflections on the lecture: Outmoded medium or instrument of inspiration? Journal of Further and Higher Education, 31(4), 397-406.

Lew, K., Fukawa-Connelly, T. P., Mejia-Ramos, J. P., \& Weber, K. (2016). Lectures in advanced mathematics: Why students might not understand what the mathematics professor is trying to convey. Journal for Research in Mathematics Education, 47(2), 162-198.

Mason, J. (2002). Mathematics teaching practice. A guide for university and college lecturers. Horwood.

Nardi, E., Ryve, A., Stadler, E., \& Viirman, O. (2014). Commognitive analyses of the learning and teaching of mathematics at university level: The case of discursive shifts in the study of Calculus. Research in Mathematics Education, 16(2), 182-198.

Neumann, R. (2001). Disciplinary differences and university teaching. Studies in Higher Education, 26, 135146.

Oikkonen, J. (2009). Ideas and results in teaching beginning maths students. International Journal of Mathematical Education in Science and Technology, 40(1), 127-138.

Paterson, J., Thomas, M., \& Taylor, S. (2011). Decisions, decisions, decisions: What determines the path taken in lectures? International Journal of Mathematical Education in Science and Technology, 42(7), 985-995.

Petropoulou, G., Jaworski, B., Potari, D., \& Zachariades, T. (2014). How do research mathematicians teach calculus? In K. Krainer \& N. Vondrova (Eds.), Proceeedings of the ninth congress of the European Society for Research in mathematics education (pp. 2221-2227). Charles University.

Pritchard, D. (2010). Where learning starts? A framework for thinking about lectures in university mathematics. International Journal of Mathematical Education in Science and Technology, 41(5), 609-623.

Pritchard, D. (2015). Lectures and transition: From bottles to bonfires? In A. Croft, M. Grove, J. Kyle, \& D. Lawson (Eds.), Transitions in undergraduate mathematics education (pp. 57-69). University of Birmingham.

Rodd, M. (2003). Witness as participation: The lecture theatre as site for mathematical awe and wonder. For the Learning of Mathematics, 23(1), 15-21.

Saroyan, A., \& Snell, L. S. (1997). Variations in lecturing styles. Higher Education, 33, 85-104.

Sfard, A. (2008). Thinking as communicating. Human development, the growth of discourse, and mathematizing. Cambridge University Press.

Speer, N., Smith, J., \& Horvath, A. (2010). Collegiate mathematics teaching: An unexamined practice. The Journal of Mathematical Behavior, 29, 99-114.

Thomas, S. (2011). An activity theory analysis of linear algebra teaching within university mathematics. Doctoral dissertation. Loughborough University.

Viirman, O. (2014a). The function concept and university mathematics teaching. Doctoral dissertation. Department of Mathematics and Computer Science, Karlstad University.

Viirman, O. (2014b). The functions of function discourse: University mathematics teaching from a commognitive standpoint. International Journal of Mathematical Education in Science and Technology, 45(4), 512-527. 
Viirman, O. (2015). Explanation, motivation and question posing routines in university mathematics teachers' pedagogical discourse: A commognitive analysis. International Journal of Mathematical Education in Science and Technology, 46(8), 1165-1181.

Weber, K. (2004). Traditional instruction in advanced mathematics courses: A case study of one professor's lectures and proofs in an introductory real analysis course. The Journal of Mathematical Behavior, 23, $115-133$.

Weber, K. (2012). Mathematicians' reflections on their pedagogical practice with respect to proof. International Journal of Mathematical Education in Science and Technology, 43(4), 463-482.

Weinberg, A., Wiesner, E., \& Fukawa-Connelly, T. (2014). Students' sense-making frames in mathematics lectures. The Journal of Mathematical Behavior, 33, 168-179.

Weinberg, A., Wiesner, E., \& Fukawa-Connelly, T. (2016). Mathematics lectures as narratives: Insights from network graph theory. Educational Studies in Mathematics, 91, 203-226.

Wittgenstein, L. (1978). Remarks on the foundations of mathematics (3rd ed.). Blackwell.

Wood, L., Joyce, S., Petosz, P., \& Rodd, M. (2007). Learning in lectures: Multiple representations. International Journal of Mathematical Education in Science and Technology, 38(7), 907-915.

Wood, L., \& Smith, G. (2004). Language of university mathematics. Paper presented at the $10^{\text {th }}$ International Congress on Mathematical Education, Topic Study Group 25. Retrieved April 9, 2010, from http://www. icme-organisers.dk/tsg25/distribution/wood.doc

Yackel, E., \& Cobb, P. (1996). Sociomathematical norms, argumentation, and autonomy in mathematics. Journal for Research in Mathematics Education, 27(4), 458-477.

Publisher's Note Springer Nature remains neutral with regard to jurisdictional claims in published maps and institutional affiliations. 